\title{
Oral tradition and communication
}

- Deepak Aryal

Oral tradition has become a domain of great interest to scholars of different disciplines of knowledge such as literature, psychology, anthropology, and philosophy. It has a huge scope for the discipline of communication too. This article presents an appraisal of oral tradition as a means of communication from one generation to another. While doing so, it deals with following issues: Can history be narrated based on oral traditions just as it is done with 'written documents'? Are the oral traditions only the sources of historiography or do they have other implications too? It also discusses whether oral traditions can be taken as valid historical sources, and, if not, whether there are means for testing its reliability.

\section{The oral tradition}

Vansina (1965) has defined oral traditions as "documents of the present" also inheriting "a message from the past." For Turner (1986), it is one of branchs of literary studies which reaches back far enough in time to invite a consideration of that crucial period in human prehistory when biological evolution overlapped with cultural evolution (p. 68). The oral traditions encompass all verbal testimonies that are reported statements concerning the past (M. Bauer and E. Bernheim, qtd. in Vansina, 1965).

According to Henige (1988), oral tradition, as a genre, should have been transmitted over several generations and to some extent be the common property of a group of people (p. 232). As Rosenberg observes, it "is the transmission of cultural items from one member to another, or others. Those items are heard, stored in memory, and, when appropriate, recalled at the moment of subsequent transmission" (1987, p. 80).

Bodhi, 3 (1), 61-68. ISSN 2091-0479. (C) 2009 Kathmandu University 
Two types of testimonies have been commonly discussed direct and indirect. Bauer and Bernheim use the term 'direct testimony' for eyewitness account, and 'indirect statement' for a reported one. Bernheim puts oral tradition in the category of direct testimonies on the grounds that both are communicated orally. It is, however, better to classify oral traditions and eyewitness accounts spearately, because each has special characterstics. Anyone can narrate and transmit the events, which they have seen, or heard from their ancestor. However, the definition of 'oral tradition' by Bauer and Berhneim does not accept that 'oral tradition' which comes from an eyewitness.

\section{Oral tradition versus written tradition}

There are different point of views in the 'East' and the 'West' regarding the interrelationship between oral and written tradition. In Vedic Hindu tradition, it is believed that both oral and written form of word existed since creation though the emphasis is primarily on oral one (For further discussion, see: Adhikary, 2003, pp. 71-73). Here, literacy was not considered a sine qua non of wisdom, and it is said that even the great grammarian Panini was not a literate (Kaviratna, 1971).

But, in the context of the West, it is widely assumed that only 'developed' societies or countries have their own advanced 'written culture' which is a sign of modernity and progress. Certeaus argues that writing as a technical instrument became divested of its Christian determinants and was re-employed as a function of new strategies of reproduction and capitalization (Ahearne, 1995). According to Certeau, 'Written tradition' symbolized the concept of modernity and the 'oral' tradition became a symbol of backward societies of nation (qtd. in Skaria, 1999). In this background, written tradition has ride on top of the orality, and a visual architecture of language has been superimposed upon restless acoustic flow of sound (Havelock, 1986, p. 149).

Bodhi, 3 (1), 61-68. ISSN 2091-0479. (C) 2009 Kathmandu University 
However, we cannot say that oral tradition does not exist. As Turner (1986) argues, the oral tradition continues in our own culture in at least two realms: liturgy and theater (p. 86). When oral and written forms of expressions are taken in the context of communication, the significance of oral tradition becomes even apparent.

\section{Oral tradition and history}

Every literate or illiterate people have a certain kind of 'oral' practice. For illiterate ones, oral communication becomes crucial and even most of the people who are literate do not write. Thus, it is a primary means of communication and a practice of daily life. People can remember and transmit many oral traditions, which they have or which they listened from their ancestor, irrespective of whether they have 'written' practice or not. Apart from regular practices of conversation, people have their legends, myths, folktales, memories, folksong, saying and proverb. However, there is no possibility of precise transmission of those oral practices from one generation to another.

Among the various kinds of historical sources, oral traditions occupy a special place. They are constantly used not only as the most important sources for the history of peoples without writing, but also as the foundation of many written sources too, especially those of classical antiquity and of the early Middle Ages. Oral traditions are historical sources of a social nature that derives from the fact that they are unwritten, they can transmit, and preservation depends on the powers of memory of successive generations of human beings. The oral tradition forms the main available source for a reconstruction of the past, who have no written culture practice and even among peoples who have writing, many historical sources, including the most

Bodhi, 3 (1), 61-68. ISSN 2091-0479. (C) 2009 Kathmandu University 
ancient ones, are based on oral traditions. Haidth ${ }^{1}$ and Mahabharat $^{2}$ are such examples.

Vansina (1965) recognized that oral materials could be of potential value to historians, whether proverbs, poetry/songs, lengthy historicized texts, or epics. He urged historians to regard these materials in much the same way as they had traditionally regarded written documents - as capable of being exploited for both direct and indirect historical information. In fact, most of the historians and ethnographers are taking oral tradition as sources of history. Case in point is India.

India became independent in 1947 and people still remember and compare the situation before and after independence. Some people are eyewitness of the whole transition period and thus have their stories. Those kinds of stories, rhyme, songs, and proverbs can help to study the perception of people and it can help to narrate cultural, political, social histories of the particular society or the nation. If we compare the written text before independent and after independent, it will give different kind of historical knowledge. Same way, we can compare the oral (linguistic) change among people. Apart from this, we can compare the perception of different generation, which may help to analyse the historical, cultural or social transition of the society.

\section{Beyond historiography}

The oral tradition is not only the sources of histories but itself a history of language, culture, society and tradition. It tells us what people speak, how they behave, how they speak or what they think and speak. It tells different people can explain the certain events differently. Yes, if the different versions of a

\footnotetext{
1 Khalidi (1995) acknolwedges Tabari who composed what was by far the most explicit defence of the Haidth method in historical writing.

2 The first section of the Mahabharata states that it was 'Ganesha' who, at the behest of Vyasa, wrote down the text to Vyasa's dictation.
}

Bodhi, 3 (1), 61-68. ISSN 2091-0479. (C) 2009 Kathmandu University 
story or event exist, the question of 'reliability' would be raised. But, if we analyze some concept like "different social groups use different varieties of language", "language reflect the society or culture in which it is used", "language shapes the society in which it is used" (Burke, 1993) etc, we can see possibilities different versions in accordance with time, space or language.

It may be in the poetic form or it may be in rhyme, story, proverbs or other forms. Sometime there may be different 'character', 'place' or 'time' in accordance with the sociocultural value and tradition. The possibilities of distortion the events privileged anywhere which should be examined. Nevertheless, oral tradition speaks the 'story' of not only the past but also of contemporary social, cultural and linguistic structure of the society. Moreover, it is also a history of language, culture and society.

\section{Validity and reliability}

Ethnologists who have attempted to study the past of people 'without writing' have faced some problems and they believe or think that oral tradition are never reliable or it may contain a certain amount of truth. They also believe that it is impossible to asses the amount of truth contained in oral tradition so it should be thoroughly examined (Vansina, 1965).

Definitely, oral tradition should be examined from the parameter of validity and reliability but the same is true with 'written text'. F. Graebner argues that the reliability of oral traditions cannot be probed unless there is some measure of agreement between various independent accounts and unless the facts conveyed correspond with those postulated by cultural historical studies (qtd. in Vansina, 1965).

In brief, question of validity and reliability is to be welcomed unless it is put with a bias to discredit the oral tradition. Any provision and instrumentation regarding its validity and

Bodhi, 3 (1), 61-68. ISSN 2091-0479. (C) 2009 Kathmandu University 
reliability will, in fact, increase the scope of examining the oral tradition in order to explore it as more authentic source of information.

\section{Concluding remarks}

Every study of the 'oral traditions' is a part of the historical study which belongs to society. Every 'oral' or 'written' tradition has some information about the past events, even if they are fiction. We collect and preserve all 'written documents' because we think it is 'real' and 'reliable' but we do not want to collect the 'oral narration'. My argument is that it is not a matter of technology, time consumption or expenses but of our conviction always emphasis that the 'written documents' have certain 'truth' than any kind of 'oral tradition'. Scholars think that every 'oral content' might be distortion by people or the right story of the past might be blurred in the transmitting process. However, in my opinion, distorted or blurred oral traditions also have 'historical', 'cultural', 'social' and 'linguistic' content and it is a part of history.

As P.C. Lloyd argues, all traditions contain some truth and the historian may be able to see in what directions distortion is most likely to have taken place and to asses better their value as historical evidence (Vansina, 1965). Oral tradition may have some confusion and contradictions, partly because of lapses of memory, partly because of possible motives for distortion.

However, this kind of problem also seems in 'written content'. As Kaviratna (1971) says, "the written word can give only an idea of the fact, but the word is not the fact itself." Whether 'oral sources' is reliable or not for particular events can be examined but it speaks the 'contemporary social, linguistic and cultural history, therefore, we have to record and analyze it. I would like to quote Rosenberg,

Oral traditions are both more specific and less ambiguous communication, because the speaker reinforces his or her specifi city of meaning with

Bodhi, 3 (1), 61-68. ISSN 2091-0479. (C) 2009 Kathmandu University 
gesture, expression, intonation, and so on, and various self-correcting mechanisms of which fi xed print is incapable. (Rosenberg, 1987, pp. 76)

Certainly, it is not the matter of advocating illiteracy, but giving oral tradition its due importance.

\section{References}

Adhikary, N. M. (2003). Hindu awadharanama sanchar prakriya (Unpublished M.A. thesis). Purvanchal University, Nepal.

Ahearne, J. (1995). Michel De Certeau: Interpretation and its other. Stanford University Press.

Burke, P. (1993). The art of conservation. New York: Cornell University Press.

Havelock, E. A. (1986). The alphabetic mind: A gift of Greece to the modern world. Oral Tradition, 1(1), 134-150. Retrieved from http://journal.oraltradition.org/

Henige, D. (1988). Oral, but oral what? The nomenclatures of orality and their implications. Oral Tradition, 3(1-2), 229-38. Retrieved from http://journal.oraltradition.org/

Kaviratna, H. (1971). Unbroken chain of oral tradition. Retrieved November 17, 2009 from http://www.theosophynw.org/theosnw/world/general/ge-kavi.htm

Khalidi, T. (1995). Arabic historical thought in the classical period. University of Cambridge.

Rosenberg, B. A. (1987). The complexity of oral tradition. Oral Tradition, 2(1), 73-90. Retrieved from http://journal.oraltradition.org/

Bodhi, 3 (1), 61-68. ISSN 2091-0479. (C) 2009 Kathmandu University 
Skaria, A. (1999). Hybrid histories: Forest, frontiers and wildness in western India. Delhi: Oxford University Press.

Turner, F. (1986). Performed being: Word art as a human inheritance. Oral Tradition, 1(1), 66-109. Retrieved from http://journal.oraltradition.org/

Vansina, J. (1965). Oral tradition a study in historical methodology. Trans. H. M. Wright. Penguin Books.

Bodhi, 3 (1), 61-68. ISSN 2091-0479. (C) 2009 Kathmandu University 